WORLD VIEW

\title{
Willingness to pay for cataract surgery in Kathmandu valley
}

\author{
M K Shrestha, J Thakur, C K Gurung, A B Joshi, S Pokhrel, S Ruit
}

Br J Ophthalmol 2004;88:319-320

See end of article for authors' affiliations

authors affilialions

Correspondence to: Mohan Krishna Shrestha, $\mathrm{BPH}$, Post box number561 , Tilganga Eye Centre, Kathmandu, Nepal; research@tilganga.com.np

Accepted for publication 18 August 2003

\begin{abstract}
Aim: A cross sectional study was carried out on 78 screened cataract patients of two screening camps in Kathmandu valley, Nepal, to assess the willingness to pay for cataract surgery.

Methods: A non-probability sampling technique with open ended and close ended questionnaires was used.

Results: The average age of patients was 68.8 years. The ratio of men and women was $0.9: 1.42 .3 \%$ (33) of patients were willing to pay for cataract surgery. Among them $48.5 \%$ (16) of people were willing to pay less than $\$ 13$ and $51.5 \%$ (17) were willing to pay more than $\$ 13$. The mean was $\$ 2.3$ (SD \$15.5) per case. Patients with bilateral cataract were more willing to pay than unilateral cases. Poverty $(44.4 \%, 20)$ was the main barrier for unwillingness to pay for cataract surgery. Other reasons were the lack of family support $(28.9 \%, 13)$, lack of knowledge of surgery and belief that it was an unnecessary procedure (15.6\%, seven), and waiting for a free surgical service $(11.1 \%$, five).

Conclusion: This study clearly indicates that although there was awareness of the availability of treatment and services provided within the reach, people are not willing to pay for the surgery and use the facility primarily because of poverty. Hence, to change patients' attitudes, a more holistic approach is needed, keeping in view the cultural, social, and economic background of the society.
\end{abstract}

W orldwide, 16 million people are blind because of cataracts and the burden of blindness is higher in developing countries ${ }^{1}$ and Nepal is no exception. ${ }^{2}$

Cataract surgery has become one of the most common cost effective ambulatory elective surgical procedures as a result of increased technology and anaesthesia costing less than $\$ 20{ }^{3}$ However, in many parts of the world, people are still in darkness, unable to utilise this technology.

Many studies show the magnitude of cataract prevalence in the community ${ }^{4}$ including a few studies published from Nepal, ${ }^{67}$ but no study has been carried out in this country to assess the willingness to pay for this sight giving procedure. Hence this study was carried out for the first time in Nepal to determine patients' willingness to pay for cataract surgery.

\section{PATIENTS AND METHODS}

A total of 78 cataract cases were selected from 705 examined from two screening eye camps of Kathmandu valley, Nepal (Sankhu Village Development Committee and Bhaktapur Municipality). All selected cases had vision less than 6/60 in one or both eyes. These two places are within half an hour drive with good transport links from Kathmandu city. Kathmandu city has all the facilities of excellent eye surgical services and the people of these two localities can easily access them. A non-probability sampling technique was used for sampling. The study design was cross sectional study containing both open ended and close ended questionnaires. Pretest was done in same types of communities. Local data enumerators were selected and trained at Tilganga Eye Centre. Willingness of patients was divided into two categories: willing to pay less than $\$ 13$ and more than $\$ 13$. Maximum and minimum amounts willing to be paid by patients were also noted.

\section{RESULTS}

The average age of patients was 68.8 years; $46.2 \%$ (36) patients were male and $53.8 \%$ (42) were female (0.9:1). Women had more severe visual impairment than men. About $61 \%$ (47) of patients were farmers, and $81 \%$ (63) were illiterate. In all, $43.6 \%$ (33) of patients were willing to pay for cataract surgery. Among them 48.5\% (16) of people were willing to pay less than $\$ 13$ and about $51.5 \%$ (17) were willing to pay more than $\$ 13$. The minimum and maximum amounts they were willing to pay was $\$ 1.3$ and $\$ 76$ respectively. The mean amount women were willing to pay was $\$ 2.3$ (SD 15.1) and for men it was $\$ 13$ (SD \$19.9). The overall mean amount people were willing to pay was \$7 (SD $\$ 15)$ per case. However, the median was zero. Bilateral cases were more willing than unilateral. Illiterate patients were less willing to pay than literate. Poverty $(44.4 \%, 20)$ was the main reason for the unwillingness to pay for cataract surgery. Other reasons were the lack of family support $(28.9 \%, 13)$, lack of knowledge of surgery and belief that it was an unnecessary procedure $(15.6 \%, 7)$, and waiting to have a free surgical service $(11.1 \%, 5)$; though they were almost blind with vision less than 3/60 (see Fig 1).

\section{DISCUSSION}

The high backlog of cataract blindness is due to ageing in the developing countries even though cost effective cataract surgery has been well defined in these regions. ${ }^{36}$

The reasons for willingness to pay in the developed and in the developing countries are not comparable. In industrialised countries, the main reason people were willing to pay is to reduce the waiting time of surgery, ${ }^{8-10}$ whereas in the

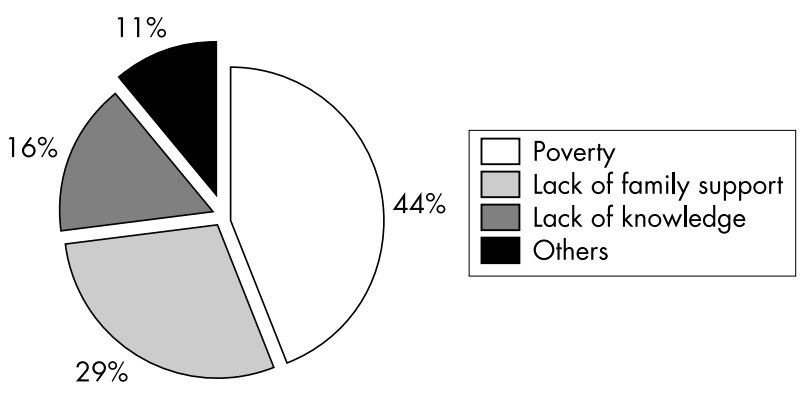

Figure 1 Reasons for patients being unwilling to pay for cataract surgery. 
developing world patients with almost blinding vision are not willing to pay even with services provided within their reach. Primary barriers are poverty, lack of family support, and lack of knowledge. A substantial number of subjects in this study were not willing to pay even $\$ 13$ for the sight giving surgery. These socioeconomic barriers are similar to other studies reported from Nepal and other developing countries. ${ }^{6} 7^{11-15}$

We also found that women were less willing to pay than men. This is probably the result of the patriarchical society prevalent in Nepal and, as reported earlier, ${ }^{16}{ }^{17}$ the male population is more mobile, whereas the female population is traditionally more confined to the household.

Bilaterally blind people were more willing to pay for the surgery than unilaterally blind patients. The patients with bilateral cataracts were desperate to have good vision to lead their daily lives whereas those with unilateral cataract and good vision in the other eye were not bothered, despite the vision in the eye with cataract being just hand movements. Nearly all patients were unaware of the complications of mature cataracts.

Most of them were waiting for free surgical camps in their locality even though they were blind with vision of less than 3/60. Moreover, Kathmandu city with all the modern surgical facilities is just half an hour drive with good transport links.

Poverty and lack of family support were the main barriers for the unwillingness, because the costs of travel to the hospital and of the follow up care are high. Additionally, the wage earning hours lost by the family made them reluctant to take scarce resources away from their children and other productive family members and use them for their old visually impaired family member who may not become economically independent.

The above findings prove that the unwillingness to pay is primary because of poverty, illiteracy, and lack of family support. The most important determinant for improving the surgical uptake with willingness to pay for surgery in the future will be the real changes in the economy of the country and an improved adult literacy in the community, especially among the female population.

\section{CONCLUSION}

This study clearly indicates that, even with awareness of the availability of treatment and good services provided within the reach of patients, people are not willing to pay for the cataract surgery and use the facility, because of poverty. Hence to change attitudes, a more holistic approach is needed, keeping in view the cultural, social, and economic background of the society.

Authors' affiliations

M K Shrestha, J Thakur, S Ruit, Tilganga Eye Centre, Kathmandu, Nepal C K Gurung, A B Joshi, S Pokhrel, Tribhuvan University, Institute of Medicine, Maharaiguni Campus, Kathmandu, Nepal

Series editors: W V Good, S Ruit

The authors have no commercial interest in the products or equipment mentioned herein.

\section{REFERENCES}

1 Thylefors B, Negrel AD, Pararajasegaram R, et al. Global data on blindness. Bull World Health Organ 1995;73:115-21.

2 Seva Foundation. The epidemiology of blindness in Nepal. Report of the 1981 Nepal Blindness Survey, 212-8.

3 Ruit S, Tabin GC, Nissman SA, et al. Low-cost high-volume extracapsular cataract extraction with posterior chamber intraocular lens implantation in Nepal. Ophthalmology 1999;106:1887-92.

4 Minassian DC, Mehra V. 3.8 Million blinded by cataract each year: projections from the first epidemiological study of incidence of cataract blindness. Br J Ophthalmol 1990;74:341-3.

5 Limburg H, Kumar R, Bachani D. Monitoring and evaluating cataract intervention in India. Br J Ophthalmol 1996;80:951-5.

6 Regmi G, Pokahrel GP. Cataract blindness prevalence in Bheri and Lumbini zones. Eye care delivery and service outcomes in south Asia. XVI Congress of Asia Pacific Academy of Ophthalmology. 4 March 1997.

7 Snellingen T, Shrestha BR, Gharti MP, et al. Socioeconomic barriers to cataract surgery in Nepal: the south Asian cataract management study. Br J Ophthalmol 1998:82:1424-8.

8 Bishai DM, Lang HC. The willingness to pay for wait reduction:the disutility of queves for cataract surgery in Canada, Denmark and Spain. $J$ Health Econ 2000;19:219-30

9 Anderson G, Black C, Dunn E, et al. Willingness to pay to shorten waiting time for cataract surgery. Health Aff (Millwood) 1997; 16:181-90.

10 Riley AF, Grupcheva CN, Malik TY, et al. The waiting game: Natural history of a cataract waitinig list in New Zealand. Clin Exp Ophthalmol $2001 ; 29: 376-80$.

11 Padmashree G, Wenkataswamy MS, Brilliant G. Social and economic barriers to cataract surgery in rural south india: a preliminary report. Visual Impairment and Blindness 1981:405-8.

12 Brilliant GE, Brilliant LB. Using social epidemiology to understand who stays blind and who gets operated for cataract in a rural setting. Soc Sci Med 1985;21:553-8

13 Brilliant GE, Lepkowski JM, Zurita B, et al. Social determinants of cataract surgery utilization in south India. Arch Ophthalmol 1991;109:584-9.

14 Johnson JG, Goode SV, Faal H. Barriers to uptake of cataract surgery. Trop Doct 1998;28:218-20.

15 Rabiu MM. Cataract blindness and barriers to uptake of cataract surgery in a rural community of northern Nigeria. Br J Ophthalmol 2001;85:776-80.

16 Lewallen S, Courtright P. Gender and use of cataract surgical services in developing countries. Bull World Health Organ 2002;80:300-3.

17 Anon. The distribution of cataract sugery services in a public health eye care program in Nepal. Health Policy 1997;42:117-33. 